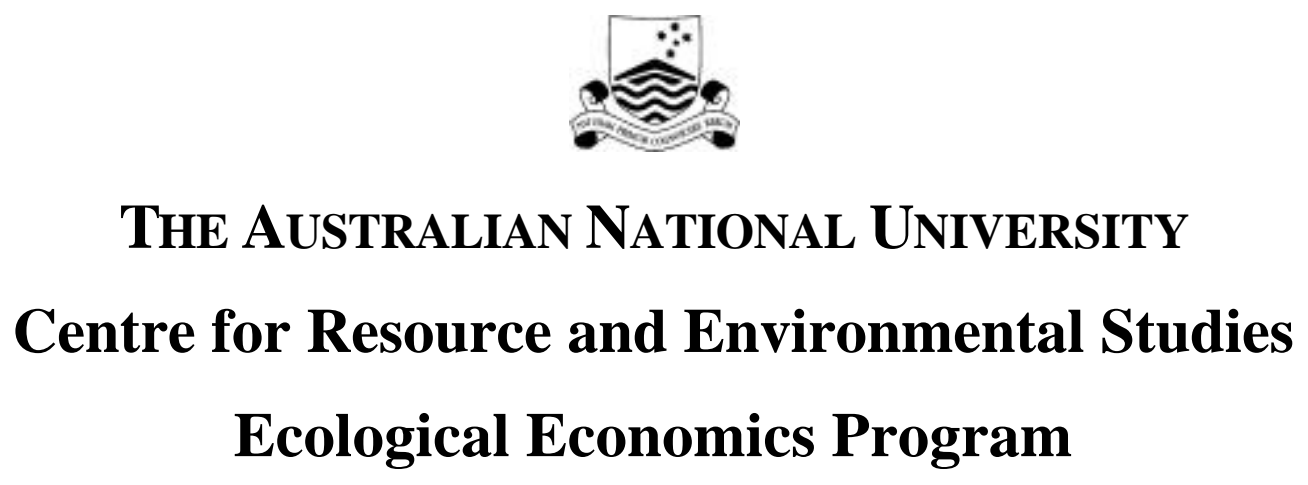

Working Papers in Ecological Economics

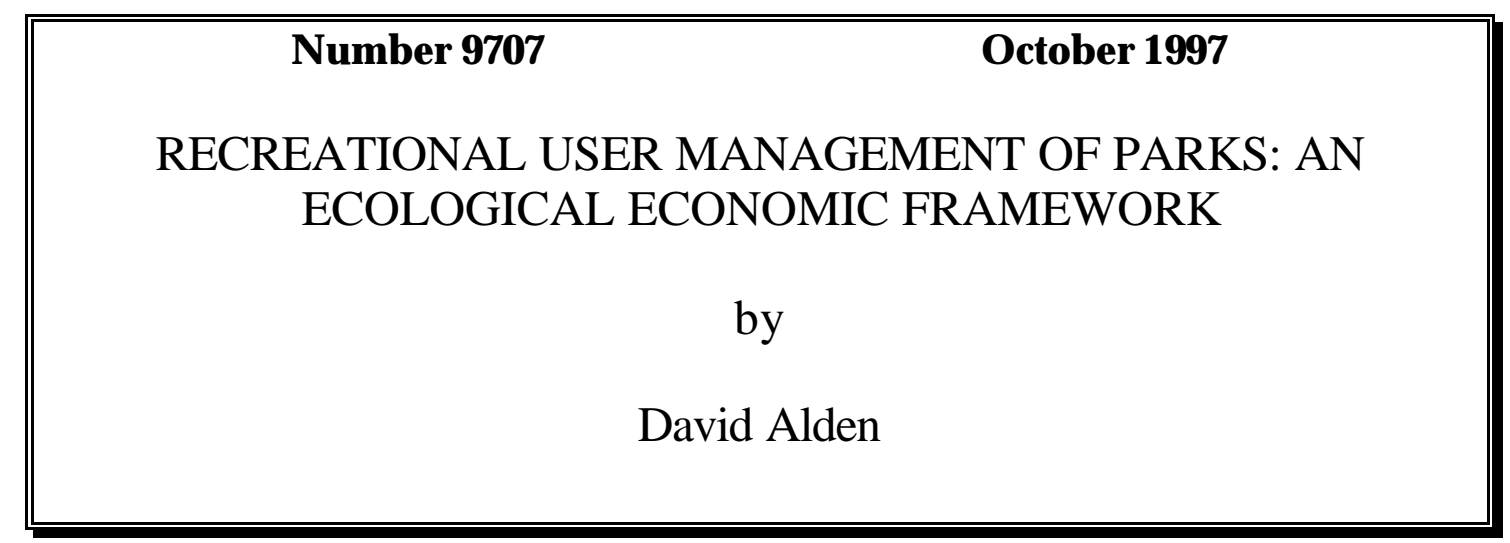

\author{
CRES, ANU, Canberra ACT 0200, AUSTRALIA \\ Tel: +61262494277 \\ Fax: +61262490757
}

E-Mail: dstern@cres.anu.edu.au

WWW: http:/ / cres.anu.edu.au/ —dstern/ anzsee/ EEP.html 
The Ecological Economics Program (EEP) was established in CRES as the result of a successful application to the Institute of Advanced Studies 1994 Strategic I nitiatives round. EEP's objective is to promote the development of ecological economics by conducting research and acting as a focal point for ecological economics activities in the Canberra region. To this end, EEP:

- hosts the office of ANZSEE, the Australia New Zeal and Society for Ecological Economics

- runs a seminar series

- $\quad$ runs a working paper series on the World Wide Web

- $\quad$ can serve as a host for individuals wishing to do ecological economics research as visitors to the ANU (Contact Mick Common for more information).

- $\quad$ supervises research students. People interested in doing a research degree in ecological economics should contact Mick Common or David Stern for more information.

The working paper series reports on research conducted in EEP by academic staff, visitors, and students, and invited seminar presenters. 


\section{Working Papers in Ecological Economics}

9601 David I. Stern. Progress on the environmental Kuznets curve?

9701 Michael Young. Water rights: an ecological economics perspective.

9702 David I. Stern and Robert K. Kaufmann. Time series properties of global climate variables: detection and attribution of climate change.

9703 Ken Menz and Katie Ellis. Fire as an economic disincentive to smallholder rubber planting in Imperata areas.

9704 Roger Attwater. Property entitlements and land reform in upland Thai catchments.

9705 Mick Common, Tim Bull, and Natalie Stoeckl. The travel cost method: an empirical investigation of Randall's difficulty.

9706 Colin Hunt. Economic instruments for environmental and natural resource conservation and management in the South Pacific.

9707 David Alden. Recreational user management of parks: an ecological economic framework. 


\title{
Recreational user management of parks: an ecological economic framework
}

\author{
Dave Alden \\ Department of Economics, University of Melbourne, \\ Parkville, Victoria 3052, Australia
}

(Current contact details: 34 Gillies Street, Curtin ACT 2605, Australia.

Tel: +61 26272 5180, E-mail: David.Alden@afma.gov.au)

\begin{abstract}
Recreational users are one of the major causes of ecosystem damage in publicly owned parks. To ensure the sustainability of these ecosystems requires that the damage impact of recreational users be managed. A constrained park management goal is proposed that allows recreational users to pursue welfare derived from park experiences, subject to non-declining ecosystem health and equity of access. Four guiding principles (adaptable community control, quantity constraints, equity of access, and least cost policy mix) are used to provide a framework for recreational user management in three groups of park ecosystem. The funding of recreational user management is explored. Classifying park ecosystems in to three groups, it was found that non-market mechanisms alone are suitable in Group 1 park ecosystems, with market mechanisms being of increasing importance use in Group 2 and Group 3 park ecosystems.
\end{abstract}

Keywords: Park management; recreational users; sustainability; market and non-market mechanisms 


\section{Introduction}

"[A]lmost 5 percent of world's land mass is now either totally or partially protected as parks and reserves, not including Antarctica" (The World Resources Institute, 1992, pp. 297). The total area protected is larger than this for the above figure includes neither marine sites, locally or provincially protected parks and reserves nor those sites less than 1000 hectares in area. Parks and reserves form an important part of the world's natural capital, especially as much of the ecosystems they contain exist in a natural state. The management of these natural capital assets is important if sustainability is to be assured.

Recreational users are one of the major causes of local and wide-scale ecosystem damage in publicly owned parks (Hammitt and Cole, 1987). To ensure the sustainability of these ecosystems requires that the damage impact of recreational users be managed. To this end, this paper suggests a management goal for 'publicly owned parks and reserves' (referred to as parks from here on) and a set of guiding principles that are grounded in an ecological economic approach to sustainability, and examines the implication of this approach for recreational user management.

A constrained park management goal is developed in Section 2, based on the hierarchical problems that Costanza (1995) suggests need to addressed for sustainability. Four guiding principles are developed in Section 3 to provide a framework for recreational user management. Section 4 examines the appropriate scale of use of parks by relating a measure of ecosystem health with the sources of the detrimental impact on ecosystems in parks attributable to recreational users. Section 5 classifies park ecosystems into three groups for the purpose of recreational user management. The guiding principles are used in Section 6 to explore the types of policies appropriate for recreational user management in the three park ecosystems identified in Section 5. Conclusions are drawn from a summary in Section 7.

\section{A park management goal for sustainability}

Costanza (1995) notes that sustainability requires ecological economics to address the three hierarchical problems of: (1) determining and ensuring that the scale of human activities are ecologically sustainable; (2) distributing resources within and between generations of humans and other species with due regard for equity; and (3) efficiently allocating the resources constrained by (1) and (2). It is also clear that policy options that arise from addressing these problems need to be delivered via effective institutions. This section employs this approach to sustainability to develop a management goal for parks.

Costanza and Patten (1995 pp. 195) give the definition of a sustainable system as "one that attains its full expected life span within the nested hierarchy of systems within which it is embedded." To attain an expected life span it is important that the health of a system is maintained in a state of good health. It follows that the non-declining health of the park ecosystem is an appropriate practical sustainability constraint for recreational user management. This constraint addresses the first of Costanza's (1995) hierarchical problems. It can also be argued that this constraint is appropriate from the ethical position that the community as a whole inherits an ecosystem and has an obligation to pass it to the community of the future in at least as good a state of health as it was inherited. By preserving the health of the park ecosystem, this constraint also addresses the between human generations equity issue and the between 
humans and other species equity issue, that form part of the second of Costanza's hierarchical problems.

If it is recognised that ecosystems generally, and especially publicly owned ecosystems within parks, are the common inheritance of all, it follows that a second constraint for recreational user management should be that usage is not determined by income level. This addresses the within human generational equity issue component of Costanza's second hierarchical problem.

I therefore suggest the following constrained goal for the management of parks that addresses the first two of Costanza's hierarchical problems: recreational users may pursue welfare derived from park experiences, subject to an ecosystem sustainability constraint of non-declining ecosystem health, and an equity of access constraint.

\section{Guiding principles for recreational user management}

To achieve the constrained management goal established in Section 2, I suggest the following four guiding principles for the management of recreational users in parks: (1) 'Adaptable community control' to address the issue of effective institutional arrangements; (2) 'Quantity constraints' to address the issue of appropriate scale, contained in the first constraint on the management goal; (3) 'Equity of access' to address the equity constraint on the management goal; (4) 'Least cost policy mix' to address the efficiency considerations in achieving the management goal. These guiding principles will now be elaborated.

\section{Guiding principle 1: Adaptable community control}

As with any management system, it is important that the institutional arrangement within which recreational users are managed is capable of effectively and efficiently achieving the management goals.

To pursue goals effectively requires that the managing body has the power to implement goal-orientated policies. In a liberal democracy this power is afforded to the managing body by the broad community if the goal being pursued is considered worthwhile, and if the managing body is determined to be bona fide. The management goal outlined in Section 2 is legitimate if the community seeks to achieve a scale of human activity in parks that is ecologically sustainable. I suggest that the managing body should be under community control. This stems from the ethical position that the community as a whole inherits parks and therefore should be responsible for their management.

It is envisioned that all parks would be managed under the control of an integrated network of local, regional, national and international 'Park Management Boards' comprised of representatives from the stakeholder groups: children, for they are "natural representatives of the future" (d'Arge, 1994 pp. 125, who goes on to advocate that children should be given "complete ownership rights of all natural species"); indigenous peoples, for they possess specific local knowledge of ecosystems; recreational users groups, for the compliance by users with decisions made by the Boards will be increased if they part-own the Boards' decisions, and if those decisions are considered acceptable and legitimate (see Hanna, 1995 for a discussion of the benefits of user participation in natural resource management); concerned community groups; individuals. It is also important to include representatives of the park authorities for they are specifically responsible of the enactment of the Boards' decisions on a daily basis. 
Information regarding the past, and likely future trends in factors affecting ecosystem health and recreational user impact on ecosystem health needs to be effectively communicated to the Boards to allow appropriate management decisions to be made.

To manage recreational users efficiently requires the managing body to choose, on the basis of least cost, between alternative policies that are perceived capable of delivering the management goal.

Adaptable management is an important aspect of recreational user management, in the face of changes in the factors that affect the health of the ecosystem and the evolution of management techniques.

\section{Guiding principle 2: Quantity constraints}

The reader will recall from Section 2 that the proposed goal for park management is constrained to ensure non-declining ecosystem health. This requires the following data. (1) The current state of health of the park ecosystem, relative to previous periods. (2) The scale of the detrimental impact by human on an ecosystem in the current period, and the factors that cause the detrimental impact. The former is required to determine whether the constraint is being met, and implies that ecosystem health can be measured. If the constraint is not being met, the latter is required to effectively manage the level of the detrimental impact by recreational users on the park ecosystem.

If there exists a downward trend in the measure of ecosystem health the setting of upper quantity limits within which users of an ecosystem can interact with the ecosystem are required. This implies that a quantity constraint on the detrimental human impact on an ecosystem in the current period is required. It should be recognised that given uncertainty as to the working of ecosystems any working value for these quantity constraints should err on the low side.

Section 4 notes an approach for measuring ecosystem health, and considers the factors that determine the scale of detrimental impacts of recreational users.

\section{Guiding principle 3: Equity of access}

To address the within (human) generational equity issue of access to parks, a constraint to the proposed park management goal, this guiding principle acknowledges that park ecosystems are the common inheritance of all, and hence, the enjoyment of parks should not be elitist with income the determinant ability to access parks. I suggest that the major implication of this guiding principle is to allow minimal impact uses in parks to be undertaken at no direct access charge to the individual.

Minimal impact uses are activities that cause the least detrimental impact upon the ecosystem, undertaken using techniques that cause the least detrimental impact upon the ecosystem. This concept is explored further in Section 4. It should be noted that this guiding principle should not take precedence over, nor deny, the rights of traditional indigenous peoples.

It could be argued that it is appropriate to charge all users, including those pursuing minimal impact uses, the administrative cost of their use that arise from admittance to site and provision of information regarding walking tracks, etc. Such a charge would seem appropriate. However, this should be seen as distinct from charging on a full user-pays basis, that covers all management costs of minimal impact uses. To do this would violate the spirit of this guiding principle. 
This guiding principle suggests that the majority of funding would need to be appropriated from sources other than from recreational users undertaking minimal impact uses. These sources of funds can be split into four categories: (1) recreational users of parks pursuing non-minimal impact uses (to be considered in Section 6); (2) non-recreational users of parks; (3) all resident and non-residents that potentially benefit from parks; (4) other sources. The latter three will be addressed here.

Two types of non-recreational user funding sources are worth noting. First, the sale of native flora and fauna would provide such a revenue source. The harvest level of the park ecosystem should be set to ensure profit maximisation, provided the harvest is less than, or equal to, the maximum sustainable yield of those species, and that the harvest does not detrimentally impact on ecosystem health in the long run. When viewing ecosystems as a whole, it is important to recognise the first of these constraints is not contained in the definition of the latter. It is possible that the sustainable harvest of one species at a particular level will alter the vigour, organisation or resilience of ecosystems (see Costanza, 1992 for a discussion of these concepts), which may reduce ecosystem health. The second source of funding from non-recreational users of parks is from the various commercial enterprises that are given permission to operate within parks. Auctioning leases and licences for the provision of various facilities such as shops, guides, tour operators, camp site management would ensure the maximum return from these operations.

Residents of a country communally own parks within their boarders. All are likely to benefit from these parks directly, as potential recreational users, or indirectly from the life support and biodiversity functions that park ecosystems provide, or the existence or bequest values that arise from these natural capital assets. A national hypothecated, that is ear-marked, progressive park ecosystem tax, based on income and taxed at source would be an appropriate vehicle for raising revenue from this funding source, being based upon ability to pay. It is generally considered that hypothecation increases acceptability. Nonresident visitors to a country are also expected to gain some of the same benefits that residents gain. A hypothecated international traveller park ecosystem tax charged at airports would be appropriate. This tax could either be a unit tax or based upon length of stay.

Other funding sources would include donations and bequests to the Park Management Board.

\section{Guiding principle 4: Least cost policy mix}

As there is an opportunity cost of financial resources for recreational management, it is important these resources are not wasted through the adoption of policies that are not least cost policies. A variety of policies will be required for recreational user management, rather than a single policy. There are three reasons for this. (1) Guiding principles 2 and 3 that relate to scale of use and equity of access considerations, respectively, are constraints on the proposed park management goal and therefore must be heeded. Each may require separate policies. (2) Different least cost policies are likely to be required for different types of park ecosystem. (3) For each park ecosystem type there are likely to be different least cost policies for addressing specific aspects of the management issue.

Section 6 will consider the least cost policy mix further. 


\section{Scale of use and the impact of recreational users}

To provide an insight into the use of the guiding principles outlined in Section 3 for recreational user management in parks, this section addresses in detail guiding principle 2: quantity constraints. First, one approach to measuring ecosystem health is outlined, that advanced by Costanza (1992) ${ }^{1}$. To be an effective constraint on the park management goal, the quantification of ecosystem health is essential. Second, an approach to measuring the detrimental impact of recreational users on ecosystems is introduced.

Costanza (1992) suggested a practical definition of ecosystem health that can be employed to direct public policy and ecosystem management. Costanza's ecosystem health index $(H)$ is a multiplicative function: $H=G^{*} O^{*} R^{2}$, where $G$ is vigour (eg. net primary product), $\mathrm{O}$ is a zero to one index of the ecosystem's organisation, and $\mathrm{R}$ is a zero to one index of ecosystem resilience. Network analysis and simulation modelling are advocated by Costanza as suitable approaches for quantifying the organisation and resilience indices.

Only if there is a downward trend in $\mathrm{H}$ should the management of the factors affecting $\mathrm{H}$ be considered, else financial resources are wasted. It should be noted that recreational users are not the only cause of a decline in $\mathrm{H}$. Non-native species, pollution, non-recreational users and natural ecosystem cycles (described by Holling, 1995) all affect $\mathrm{H}$. If it is established, via measurement or expert judgement, that recreational users are in part or fully responsible for the decline in $\mathrm{H}$ then the management of their impact on ecosystem health is appropriate.

An impact identity equation, analogous to the famous 'I=PAT' identity of Ehrlich and Holdren (1971), can be used to conceptualise factors which affect the detrimental impact on a park ecosystem in the current period (I) of recreational users.

$\mathrm{I}=\mathrm{P}^{*} \mathrm{~V} \mathrm{~V}^{*} \mathrm{~T}$

where $\mathrm{P}$ is the user population in the current period, $\mathrm{V}$ is the number of visits per capita of the user population in the current period, $T$ is the quantity of damage done to the ecosystem, due to the technology employed, per visit in the current period.

Meadows (1995) noted that although the I=PAT formula provides a lens through which to see the environmental situation, the formula has been criticised for not making explicit which factors influence the variables on the right hand side of the equation. Effective recreational user management policy suggestions require that this criticism be explicitly addressed when considering $I=P^{*} V^{*} T$.

Over time $\mathrm{P}$ and $\mathrm{V}$ have tended to increase. For example, over the five years to 1993, there was growth in visitor numbers at almost all World Heritage sites, with approximately 40 million visitors to sites in 1993 (The World Heritage Centre, 1994). T has increased in recent years with the introduction of such technology as off-road recreational vehicles and mountain bikes on natural land forms, and speed boats and jet-skis to waterways for recreational use. It is therefore of no surprise that I has increased, and is likely to increase in the future. This suggests that, if not addressed, park ecosystem health will reduce in the future. However, it is also possible to allow $\mathrm{P}$ and $\mathrm{V}$ to increase, while reducing I, through addressing ways in which $T$ can be reduced. $T$ can be thought of as:

$T=f(A, Q, S, W)$.

\footnotetext{
${ }^{1}$ For a discussion of other measures of ecosystem health see Hannon (1992).

${ }^{2} \mathrm{G}$ rather than Costanza's $\mathrm{V}$ is used here to denote vigour, for $\mathrm{V}$ is used latter in the article.
} 
A is a malignancy index of the detrimental impact on the park ecosystem of activities (eg. camping, recreational fishing and hunting, four-wheel driving, walking) pursued per visit, aggregated across park users. A variety methods for determining such an index could be developed and employed, that vary in their data requirements and crudeness. At one extreme, an index could be constructed based upon expert opinion of the detrimental impact on park ecosystems of the activities recently undertaken in the park. At the other extreme, an index could be based upon detailed sampling of the impact on biophysical indicators of the activities recently undertaken in the park. The indicator measures could include, for example, compaction, loss and gullying of soil, disturbance of species and habitat, vegetation loss, tree damage, root exposure, spread of weeds, etc. (see Hammitt and Cole, 1987 and Turner, 1994 for discussion of methods for measuring the impact of various recreational activities).

$Q$ is a malignancy index of the detrimental impact on the ecosystem of the techniques employed per activity, aggregated across park users. To pursue camping as an activity, for example, there exists a number of possible techniques (eg. fires used, stoves only, no flames). This index could use the same measurement approaches as those suggested for determining $A$, but as relate to the variety of techniques employed per activity.

$S$ is an index of the level of 'stress' upon the park ecosystem at the beginning of the period, which could be based on a weighted decay function of the cumulative number of periods in which $\mathrm{H}_{\mathrm{t}-1}<\mathrm{H}_{\mathrm{t}-2}$, where $\mathrm{H}_{\mathrm{t}-1}$ is the level of Costanza's (1992) ecosystem health index in the previous period (see Holdren et al., 1995 for an alternative proxy for stress).

W is an 'awareness' index that reflects recreational user's awareness of the nature and health of the ecosystem, and the need for recreational user management. The 'awareness' index could be a weighted inverse function of $\mathrm{V}$, and to a lesser extent $P$, and a positive function of the quantity of effective on-site and off-site education of recreational users toward behaviour that reduces I. A crude proxy for the latter is the expenditure on recreational user education.

The reader will have noted that the impact equation can be used to manage users of other ecosystems, such as commercial fisheries or forestry.

$A$ reduction in $T$, and hence $I$, occurs when $A, Q$ and $S$ are reduced and when $W$ is increased. The development and use of policies to influence $T, P$ and $V$ will be explored in Section 6 . First, Section 5 will consider a range of ecosystems types for the purposes of recreational user management.

\section{Ecosystem classification}

For the purposes of management, ecosystems can be classified into three groups by consideration of ecological importance and reversibility if lost. This follows the approach by King (1994) to natural capital classification. At one extreme there are ecosystems which are ecologically important and/or irreversibly lost if destroyed (Group 1). At the other extreme there are ecosystems which are not ecologically important or are replaceable (Group 3). Between these two extremes there are ecosystems which are ecologically important, but non-essential, and can be partially restored if lost (Group 2).

King examines a number of approaches for measuring 'importance' and 'reversibility' of natural capital if lost, and hence ecosystem classification. King also notes that the allocation of particular ecosystems to specific Groups will be made with due regard to political and economic debate, and not only scientific 
considerations. It is also appropriate that this debate considers the expected life span of the ecosystem, and hence whether a decline in ecosystem health is a result of the system approaching the end of its life.

In the context of this paper, the three groups of ecosystems can be thought of as referring to different types of parks that require, in order, decreasing levels of ecosystem preservation as a result of them being reversible if destroyed: World Heritage Areas (Group 1 parks); National Parks and reserves (Group 2 parks); provincial and local parks and reserves (Group 3 parks). Alternatively, the groupings could be applied to separate areas within a specific park: a core zone (Group 1 park ecosystems) that contains the most ecologically important ecosystems and is irreversibly lost if destroyed; a buffer zone (Group 2 park ecosystems) that is adjacent to the core; and a transition zone (Group 3 park ecosystems) that is adjacent to non-park land. For the purposes of the remainder of this article the latter naming system will be used to refer to both ecosystems within a single park and different types of park.

\section{Appropriate policy mix for recreational user management}

If a downward trend in park ecosystem health is deemed to be attributable to the detrimental impact of recreational users, the implementation of the appropriate policy mix for the management of recreational users is required. The management techniques available depend upon the group to which the park ecosystem belongs. This section discusses, with reference to the equity of access guiding principle and the park ecosystem classification, where it is appropriate to use market incentives as a management tool to reduce the detrimental impact of recreational users on park ecosystem health, and where non-market techniques are important (for a wider discussion of recreation management techniques see Hammitt and Cole, 1987). It is not intended for this section to be a survey of all the available policy options to determine a particular least cost policy option for each park ecosystem type. This is because the determination of a least cost policy mix option is an empirically based modelling exercise only appropriate at the level of individual park sites, based upon the park's level of ecosystem health, and current and potential mix and levels of activities and techniques undertaken by recreational users.

As the reader will recall from Section 4 the detrimental impact of recreational users on a park ecosystem is determined by the level of $P, V$ and $T$, with the latter being a function of $A, Q, S$ and $W$.

To ensure as much freedom of choice as possible for individual recreational users, I suggest that policies for reducing the detrimental impact of recreational users on park ecosystems should concentrate upon, in order of descending priority: increasing $\mathrm{W}$; reducing $A$; reducing $Q$; reducing $V$; and reducing $P$. As a result, $S$ will, intertemporally, be reduced.

A number of non-market and market based management techniques can be used to reduce $T$. It is likely that a least cost policy will to reducing $T$ will be a mix of non-market and market based management approaches.

Non-market based management techniques that directly reduce $A$ and $Q$, increase $\mathrm{W}$ and, intertemporally, reduce $\mathrm{S}$ include: moral suasion approaches; 'minimal impact usage' education programs for users; and site hardening through the introduction of such things as 'board walks' and gravel paths. These approaches could, in principle, be used in all three ecosystem groups. However, extensive use of site hardening in Group 1 park ecosystems is undesirable for it is likely to directly reduce the park ecosystem health. 
Common (1995) notes that moral suasion is not usually considered by economists as an inappropriate policy option, primarily because it undermines consumer sovereignty by implying that individual's preferences are wrong. Common notes that appropriately undertaken moral suasion is worthy of consideration in ecological economic policy formulation. There are two major benefits of employing education and moral suasion as means of encouraging recreational users to reduce $\mathrm{T}$ : (1) freedom of choice is preserved, or at least perceived freedom of choice in the face of moral suasion; and perhaps more importantly (2) the alteration of individual behaviour can occur quickly and profoundly. The 'Tread Lightly!' campaign, initiated in the USA in 1989, is an excellent example of this type of education and moral suasion exercise directed at recreational users (Scudmore, 1996). 'Tread Lightly!' attempts to make individuals aware that: "(i) almost all damage to the environment is caused through a lack of knowledge; and (ii) teaching folk how to prevent this is better than banning them" (Scudmore, 1996 pp. 14). A minimal impact strategy, comprising best minimal impact practices, codes and ethics for all outdoor recreational pursuits, is currently being developed on a national basis with inputs from major stakeholders.

Given the criterion upon which ecosystems were classified in Section 5, it is appropriate that the permitted activities and techniques for undertaking activities should vary between the groups. For Group 1 park ecosystems, only minimal impact uses, as defined in guiding principle 3, can be allowed. This is because Group 1 park ecosystems are ecologically important and/or are irreversible lost if destroyed. Progressively more damaging activities and techniques can be pursued in park ecosystem Groups 2 and 3, respectively. The extent to which more damaging activities and techniques can be employed in park ecosystem Groups 2 and 3 will depend upon their respective ecological importance, level of park ecosystem stress at the beginning of the current period, and ability to be repaired/replaced, naturally or with human intervention, if damaged/destroyed. These two park ecosystem Groups will be considered together here. However, it should be noted that when the least cost policy mix is being developed for an individual park ecosystem site policy should reflect the importance of the ecosystem and the degree of irreversibility if lost, which will in turn influence the permitted activities and techniques.

The extent to which market mechanisms can be employed in the three park ecosystem groups will now be explored, together with further examination of the use of non-market approaches.

\section{Group 1 park ecosystems}

As discussed above only minimal impact uses can be allowed for Group 1 park ecosystems. Given that guiding principle 3 requires equity of access, it is inappropriate to use market incentives to reduce the detrimental impact on park ecosystems via a reduction in the user population or the number of visits per capita of the user population in the current period. Therefore a quota approach should be applied to reduce, for equity reasons: visits per capita of the user population first; the user population second, if the detrimental impact on the ecosystem continues to reduce park ecosystem health when the visits per capita of the user population in the current period is one. A random draw lottery is an equitable method for determining individuals or groups of individuals in the user population that may have park access in the current period. There is no role for market mechanisms in the management of Group 1 park ecosystems. 


\section{Group 2 and Group 3 park ecosystems}

For Group 2 and Group 3 park ecosystems, it is possible to reduce the detrimental impact on the ecosystem by a reduction in the quantity of damage done to the ecosystem due to the technology employed per visit. If minimal impact uses are currently being undertaken, the management approaches for Group 1 park ecosystems should be adopted.

The reader will recall from Section 3 that revenue raised from non-minimal impact users was considered to be an appropriate source of funding for the provision of park management. This will now be considered in conjunction with addressing the issue of park ecosystem damage reduction.

Market incentives can be used to reduce the detrimental impact on park ecosystems due to the technology employed per visit ( $T$ ) by: (1) altering the mix of activities pursued per visit towards those more benign with respect to ecosystem health (reducing A); and/or (2) altering the mix of techniques employed in each activity towards those more benign with respect to ecosystem health (reducing Q); (3) adoption of management techniques that decreasing the detrimental impact of each technique on ecosystem health.

To explore the use of market and non-market approaches the following discussion will consider some methods for reducing the detrimental impact on park ecosystems of one activity: the recreational use of off-road recreational vehicles (ORVs), arguably one of the most damaging recreational activities (see Webb and Wilshire, 1983 for a wider discussion of the environmental impacts and management of ORVs).

To alter the mix of activities pursued per visit it is appropriate to charge a user fee, or increase the fee if none currently exists, for the recreational use of ORVs. Charging users on a per time block (eg. hourly, half-day, weekend) and/or per track use basis would be an appropriate approach (Marriott, 1993). This will encourage users to seek cheaper substitutes and alternatives eg. undertake the same activity on land that is not important ecologically, if a lower use fee is charged, or switch to other activities such as canoeing or walking. As the latter activities are comparatively benign with respect to ecosystem health, a low or no charge would be associated with these activities. It would be appropriate to charge a higher use fee for ORV use on Group 2 park ecosystems than on Group 3 park ecosystems. If ORV use becomes elitist as the charge for use increases, it can be argued on equity of access grounds (guiding principle 3) that the use of ORV s should be prohibited. If rich ORV users foresaw such a situation, it may be in their own best interests to directly or indirectly subsidise poor ORV users who could not afford the high use fees. In terms of total user access to ORV activities, although such schemes would be a zero-sum game in the presence of scarce use rights, they ensure the guiding principle of equity of access is addressed, while securing continued access of rich ORV users, as a group, to this activity. Perhaps the easiest of all such subsidising schemes to monitor is for local, regional or national ORV user associations to sponsor ORV tours open to underprivileged individuals nominated by suitable charity organisations. The Park Management Board would need to monitor such a scheme.

A variety of market mechanisms exist to alter the mix of techniques employed in the recreational use of ORVs towards those which are more benign with respect to ecosystem health. Two are noted. (1) A lower price per passenger could be charged the greater the number of passengers per vehicle, to 
encourage users to share vehicles. (2) Access to ORV tracks could be restricted to particular users, through the issuing of licences for which a fee would be charged. Regulations attached to licences would stipulate the manner in which ORV use could be undertaken eg. no off-track driving, minimum number of passengers per vehicle, maximum number of visits per period, the requirement for licence holder to periodically attend or pass a training course in minimum impact driving, etc. A use fee per visit is also required in this system.

To reduce the damage done to the ecosystem from any specific technique employed in the recreational use of ORVs differential pricing can be applied to tracks, to reflect the scarcity value for potential use. High licence fees and/or use fees should be charged for tracks under stress. Again, if there is a tendency for the use of these tracks to become elitist, the use of ORVs should be prohibited on equity grounds. Again, rich ORV users may wish to subsidise poor ORV users to prevent prohibition of use.

Damage to an ecosystem from any specific technique of ORV usage can also be achieved by non-market based management techniques, such as the rotation of tracks available for use to reduce stress on tracks or specific track closure during fauna breeding seasons.

\section{Monitoring}

Monitoring of the behaviour of recreational users and their impact is vital for successful management. Where possible a policy that encourages selfmonitoring of users, as individuals and as a group, should be encouraged. This makes users responsible for their own actions as well as for monitoring and influencing ecosystem health damaging behaviour of other users directly, or indirectly through the reporting of the user and their behaviour to park authorities. Self-monitoring of recreational users will also be a low cost approach to monitoring the behaviour of recreational users, compared with extensive use of ranger patrols, for example. It should be noted that to be effective a selfmonitoring approach should be actively supported by the park authority via proactive user education and close liaison with major user groups, and hence will not be a monitoring approach that incurs zero financial costs.

The cost of monitoring the behaviour of recreational users in each of the Group 2 and Group 3 park ecosystems are likely to be greater than that incurred in Group 1 park ecosystems. There are two reason for this. First, multiple activities and techniques are permitted in Group 2 and Group 3 park ecosystems, while only the minimal impact activity and technique are permitted in Group 1 park ecosystems. Second, and stemming from the first, there are likely to be greater numbers of recreational users in Group 2 and Group 3 park ecosystems than Group 1 park ecosystems.

\section{Summary and conclusions}

When contributing to policy recommendations for the management of specific stocks of natural capital, such as ecosystems within publicly owned parks and reserves, ecological economics can provide a framework for sustainability.

A constrained park management goal has been proposed here that allows recreational users to pursue welfare derived from park experiences, subject to non-declining ecosystem health and equity of access.

Where the decline in park ecosystem health results from the detrimental impact of recreational users, policies are required to reduce this impact. Resulting from a suggested set of guiding principles, Table 1 summarises the 
extent to which there is a role for non-market and market mechanisms in reducing the detrimental impact of recreational users on park ecosystems. It was found that non-market mechanisms alone are suitable in Group 1 park ecosystems, with market mechanisms being of increasing importance use in Group 2 and Group 3 park ecosystems. The priority order in which the policy tools should be applied, to ensure maximum freedom of choice for individual recreational users, is also included.

It has been stressed that control of recreational user management should lie with the community, via Park Management Boards and that the least cost policy mix to achieve the constrained management goal should be pursued. It remains for ecological economics to determine the appropriate mechanisms for the establishment of such Boards and for appropriate policy mixes at the level of individual parks. Given the demands upon park ecosystems, it is unlikely that sustainability will be achievable without effective proactive recreational user management.

\section{Acknowledgments}

I am grateful to David McGregor, John Proops, my ecological economics students, and a number of participants at the inaugural 'Ecological Economics Conference' of ANZSEE (Coffs Harbour, 19-23 November 1995) for constructive comments on earlier versions of this paper. The comments of two anonymous reviewers greatly improved the quality and structure of this paper, for which I am most grateful.

\section{References}

Common, M., 1995. What is ecological economics. Paper presented at the inaugural ecological economics conference of the Australia and New Zealand Society for Ecological Economics, Opal Cove Resort, Coffs Harbour, NSW, Australia, 19-23 November 1995.

Costanza, R., 1992. Toward an operational definition of ecosystem health. In: Costanza, R., Norton, B.G. and Haskell, B.D. (Editors), 1992. Ecosystem Health: New Goals for Environmental Management, Island Press, Washington, DC, pp. 239-256.

Costanza, R., 1995. Ecological economics - the policy dimensions: integrated envisioning, modeling, and implementation of sustainable and desirable society. Paper presented at the inaugural ecological economics conference of the Australia and New Zealand Society for Ecological Economics, Opal Cove Resort, Coffs Harbour, NSW, Australia, 19-23 November 1995.

Costanza, R. and Patten, B.C., 1995. Defining and predicting sustainability. Ecological Economics, 15: 193-196.

d'Arge, R.C., 1994. Sustenance and sustainability: how can we preserve and consume without manor conflict? In: A. Jansson, M. Hammer, C. Folke and R. Costanza (Editors), Investing in Natural Capital: The Ecological Economics Approach to Sustainability, Island Press, Washington, D.C., pp. 13-127.

Ehrlich, P. and Holdren, J., 1971. Impact of Population Growth. Science, 171: 1212-1217.

Hammitt, W.E. and Cole, D.N., 1987. Wildland recreation: ecology and management, John Wiley \& Sons, New York, 341 pp.

Hanna, S., 1995. Efficiencies of user participation in natural resource management. In: S. Hanna and M. Munasinghe (Editors), Property Rights and the Environment: Social and Ecological Issues, The Beijer International 
Institute of Ecological Economics, Stockholm and The World Bank, Washington D.C., pp. 59-67.

Hannon, B., 1992. Measures of economic and ecological health. In: Costanza, R., Norton, B.G. and Haskell, B.D. (Editors), 1992. Ecosystem Health: New Goals for Environmental Management, Island Press, Washington, DC, pp. 207-222.

Holling, C.S., 1995. Sustainability: the cross-scale dimensions. In: M. Munasinghe and W. Shearer (Editors), Defining and Measuring Sustainability: The Biophysical Foundations, The World Bank, Washington, D.C., pp. 65-75.

King, D.M, 1994. Can we justify sustainability? New challenges facing ecological economics. In: A. Jansson, M. Hammer, C. Folke and R. Costanza(Editors), Investing in Natural Capital: The Ecological Economics Approach to Sustainability, Island Press, Washington, D.C., pp. 323-342.

Marriott, K., 1993. Pricing policy for User Pays. Australian Parks \& Recreation, 29(3): $42-45$.

Meadows, D., 1995. Who Causes Environmental Pollution. International Society For Ecological Economics Newsletter, 6(3): 1, 8.

Scudmore, J., 1996. The main arbiter of your behaviour is you! Australian Parks \& Recreation, 32(2): 11-17.

The World Heritage Centre, 1994. The World Heritage Newsletter No. 4, The World Heritage Centre, United Nations Educational, Scientific and Cultural Organization, Paris.

The World Resources Institute, 1992. World Resources 1992-93: A Guide to the Global Environment, Oxford University Press, Oxford.

Turner, A., 1994. Managing impacts: measurement and judgement in natural resource management. In: D. Mercer (Editor) New viewpoints in Australian Outdoor Recreation and Planning, Hepper Marriott and Associate Publishers, Williamstown, Victoria, Australia, pp. 129-140.

Webb, R.H. and Wilshire, H.G. (Editors), 1983. Environmental Effects of OffRoad Vehicles: Impact and Management in Arid Regions, Springer-Verlag, New York, 534 pp. 


\section{Table 1}

Policy tools to reduce detrimental impact of recreational users on park ecosystems

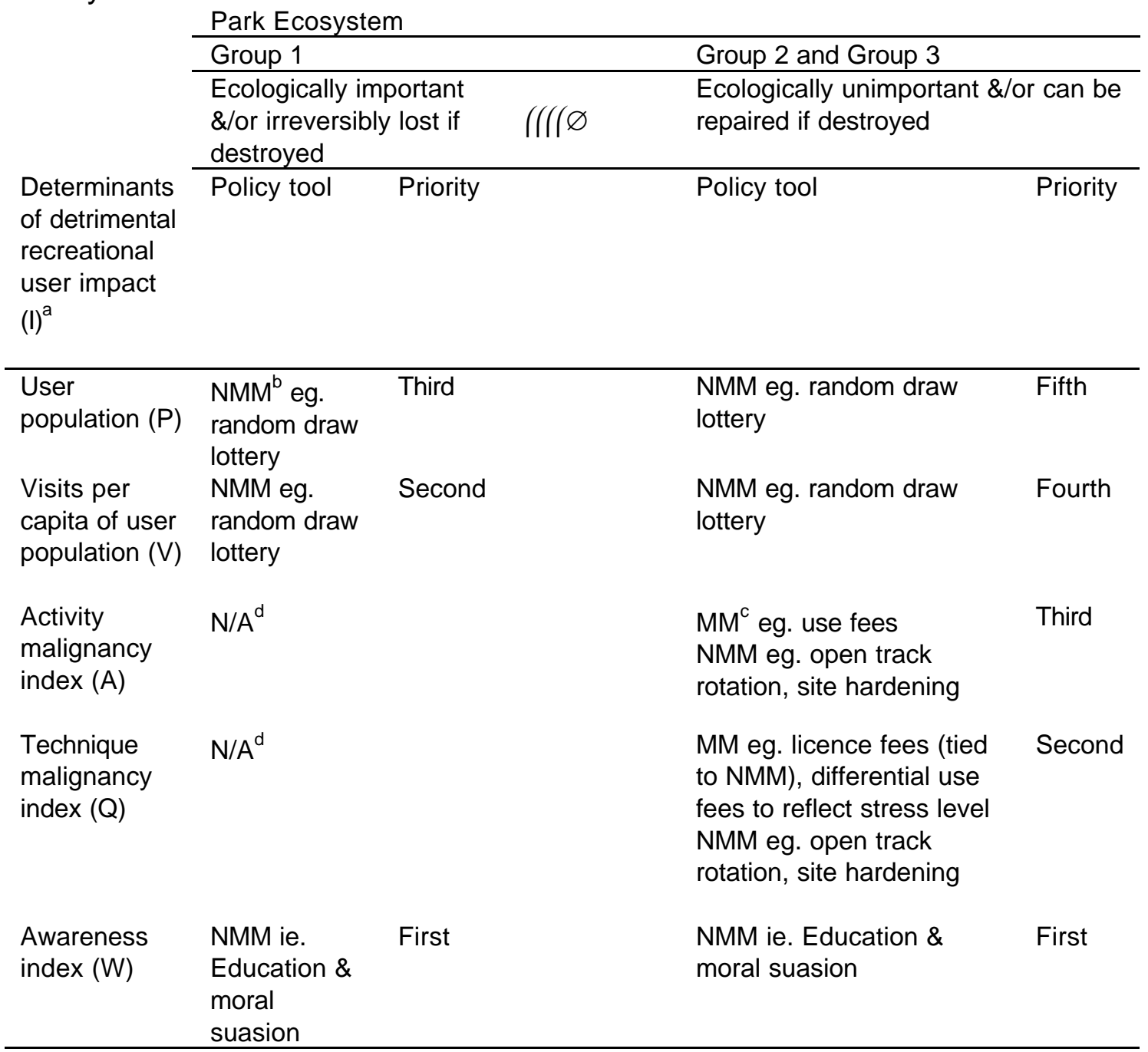

${ }^{\text {a }}$ Stress is not identified for policies cannot reduce stress in the current period.

${ }^{\mathrm{b}}$ Non-market mechanism.

${ }^{c}$ Market mechanism.

${ }^{\mathrm{d}}$ No policy tool necessary as minimal impact activity and technique is the only permitted recreational use. 